\title{
DC-link sensorless control strategy for grid-connected PV systems
}

\author{
Mostafa Ahmed $^{1,2}\left(\mathbb{D} \cdot\right.$ Mohamed Abdelrahem $^{1,2} \cdot$ Ahmed Farhan $^{3} \cdot$ Ibrahim Harbi $^{1,4} \cdot$ Ralph Kennel $^{1}$
}

Received: 14 July 2020 / Accepted: 22 January 2021 / Published online: 24 February 2021

(C) The Author(s) 2021

\begin{abstract}
Sensorless strategies become very popular in modern control techniques because they increase the system reliability. Besides, they can be used as back-up control in case of sensor failure. In this paper, a DC-link sensorless control approach is developed, which is suited for grid-connected PV systems. The studied system is a two-stage PV scheme, where the DC-DC stage (boost converter) is controlled using an adaptive step-size perturb and observe ( $\mathrm{P} \& \mathrm{O})$ method. Further, the inverter control is accomplished by voltage oriented control (VOC). Generally, the VOC is implemented with two cascaded control loops, namely an outer voltage loop and an inner current loop. However, in this work, the outer loop is avoided and the reference current is generated using a losses model for the system. The losses model accounts for the most significant losses in the PV system. Moreover, particle swarm optimization (PSO) is utilized to compensate for the unmodeled losses. The PSO is executed offline for the purpose of calculation burden reduction. The proposed approach simplifies the cascaded VOC strategy and eliminates the DC-link voltage sensor, which in turn decreases the cost of the system. Finally, the proposed technique is compared with the conventional one at different atmospheric conditions and validated using MATLAB simulation results.
\end{abstract}

Keywords Sensorless DC-link control · PV systems · Adaptive MPPT · VOC

\section{Introduction}

The energy production from conventional sources is subjected to reduction, and the current trend is directed to utilizing renewable energy systems (RESs). RESs provide an excellent alternative due to the expected lack of fossil

Mostafa Ahmed

mostafa.ahmed@tum.de

Mohamed Abdelrahem

mohamed.abdelrahem@tum.de

Ahmed Farhan

afm01@fayoum.edu.eg

Ibrahim Harbi

ibrahim.harbi@tum.de

Ralph Kennel

ralph.kennel@tum.de

1 Institute for Electrical Drive Systems and Power Electronics, Technical University of Munich (TUM), Munich , Germany

2 Electrical Engineering Department, Faculty of Engineering, Assiut University, Assiut, Egypt

3 Electrical Engineering Department, Faculty of Engineering, Fayoum University, Fayoum, Egypt

4 Electrical Engineering Department, Faculty of Engineering, Menoufia University, Shebin El-Koum, Egypt fuel $[1,2]$. Additionally, the environmental issues encourages many organizations to employ such sources in different power applications, especially for grid-integration [3]. Hydro energy, wind energy and solar energy are the most popular systems to be utilized. The RESs provided nearly $26.5 \%$ of the total energy world's consumption by end of 2017 [4]. Different countries like China, USA, Germany, Spain, etc. play an important role in the energy market [5]. The vision of Germany is to reach $65 \%$ of its gross energy consumption by 2030 only from renewable energies [6]. Literally, photovoltaic (PV) energy is the most abundant source among renewable energy sources. It reaches the earth in different forms like light and heat [7].

PV systems are widely integrated into the grid. They provide a clean, silent and efficient energy profile. The grid-connected PV systems can be mainly classified into single-stage and two-stage topologies [8,9]. In the singlestage, the maximum power point tracking (MPPT) operation, the active and reactive power control are included in the inverter control. However, in the two-stage topology, the MPPT is decoupled from the inverter control and implemented separately in the DC-DC converter stage [10]. The two-stage topology provides several merits including flexible arrangement of the PV modules [9]. Besides, the DC-DC 
converter increases the PV voltage to a proper level for grid connection and decouples the MPPT function from the inverter control [10,11]. Furthermore, the boost converter minimizes the need of low-frequency transformer at the inverter output. Thus, the overall control structure is simplified and the cost is reduced [11].

In the literature, many techniques are investigated to control active and reactive power for grid-connected inverters $[12,13]$. However, the most commonly methods are the voltage oriented control (VOC) and the direct power control (DPC) [14]. The DPC technique is formulated according to the error between the instantaneous values of the active and reactive power and their references knowing the position (angle) of the grid voltage [15]. Hence, the switching actions of the inverter can be directly obtained using a lookup table without the need of modulator. As a result, the DPC presents variable switching frequency; also the power waveform exhibits a significant ripple content. The VOC depends on two cascaded loops to manage the inverter control. The outer loop or voltage loop is linked to the DC-link capacitor voltage, where a PI controller is employed to generate the reference current for the inner or current loop. Then, two PI controllers are used to control the currents, and hence, the active/reactive power control can be achieved [16]. Recently, predictive control techniques are getting more interest due to good transient response [17]. Additionally, some conditions and constrains can be added to the algorithm to impose certain tasks $[18,19]$. However, the large computation burden and variable switching frequency are major drawbacks of this control strategy [20,21].

Sensorless control strategies are advantageous. In fact, they bring numerous benefits to the system. From cost's point of view, the cost of the system is greatly reduced. Further, from control perspective, the control structure is simplified [22]. Actually, some efforts have been made to reduce the number of required sensors, hence achieving sensorless control of the grid-connected inverter. Some researches focus on eliminating the PV voltage and/or the PV current sensors [23-26]. However, this may lead to the loss of maximum power extraction and the system behavior will be deteriorated. Limited work realizes DC-link sensorless control of PV systems. In [9], a single-phase two-stage grid-connected system is implemented, where a compensating current is proposed to account for the losses of the system. This current is calculated using artificial neural network algorithm. A losses factor is proposed for three phase grid-connected system in [11]. This factor is applied to estimate an approximate value of the DC voltage for the outer loop (voltage loop). Nevertheless, a constant value was set for this factor, though the losses of the PV system are atmospherically dependent.

In this paper, a sensorless DC-link control approach is proposed, where a simple but effective losses model for the two-stage grid-connected PV system is developed. The losses

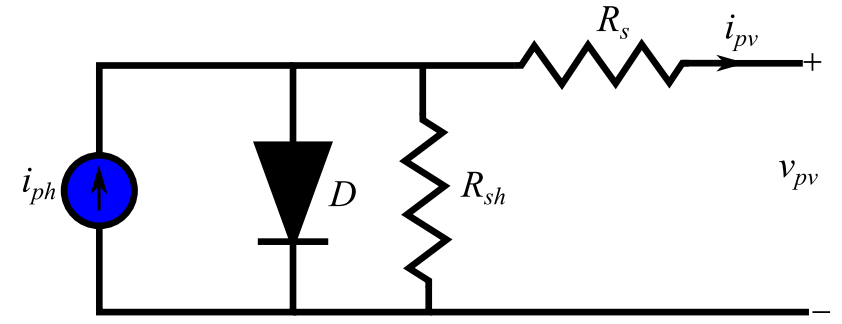

Fig. 1 Single-diode equivalent circuit of the PV source

model considers the most notable losses in the PV system to guarantee a stable voltage at the input of the inverter. Furthermore, additional losses component was added and tuned using particle swarm optimization (PSO) technique to regard the unmodeled losses. Thus, the outer voltage loop is removed and the reference current is computed directly from the generated PV power and the developed losses model. The current generation is based on the fact that the DC-link voltage will stabilize if the extracted power from the PV source is fed into the grid, which guaranties balance of the energy. Eliminating the outer loop (i.e., no need for voltage sensor) not only reduces the cost but also enhances the transient performance. Moreover, the overall control structure will be simplified. To maximize the power generation, an adaptive perturb and observe $(\mathrm{P} \& \mathrm{O})$ technique is employed to minimize the steady state oscillatory behavior of the conventional MPPT algorithms. Finally, the proposed technique is compared with the conventional cascaded structure of the VOC at different atmospheric conditions and validated using simulation results.

The rest of this paper is organized as follows: Sect. 2 presents the model of the grid-connected PV system including the losses. Section 3 explains the MPPT operation and the conventional VOC for the PV scheme, while the proposed sensorless DC-link control strategy with PSO is investigated in Sect. 4. Section 5 provides the simulation results, and the paper is concluded with Sect. 6 .

\section{Modeling of the grid-connected PV system}

\subsection{PV source model}

Figure 1 shows the single-diode equivalent circuit of the PV module, where the current-voltage (I-V) characteristics of the PV generator can be expressed as [27]

$i_{\mathrm{pv}}=i_{\mathrm{ph}}-i_{o}\left[e^{\left(\frac{v_{\mathrm{pv}}+i_{\mathrm{pv} R_{s}}}{n N_{s} v_{t}}\right)}-1\right]-\frac{v_{\mathrm{pv}}+i_{\mathrm{pv}} R_{s}}{R_{\mathrm{sh}}}$,

where $i_{\mathrm{ph}}$ is the photovoltaic current, $n$ is the diode ideality factor, $i_{o}$ is the saturation current of diode, $R_{S}$ is the series resistance, $R_{\mathrm{sh}}$ is the shunt resistance, $v_{t}=k T / q$ is the ther- 


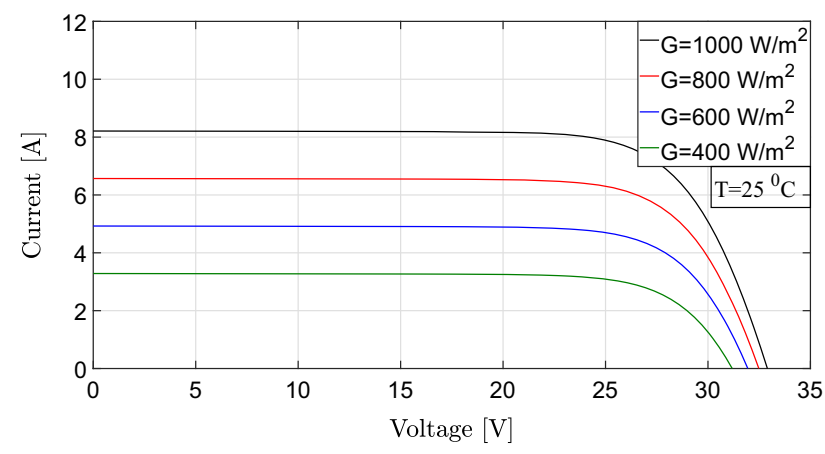

Fig. 2 I-V characteristics of the PV module at different radiation conditions and constant temperature

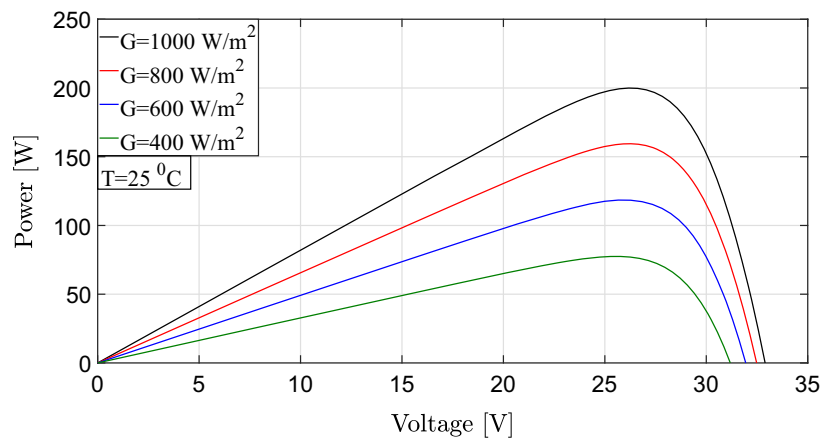

Fig. 3 P-V characteristics of the PV module at different radiation conditions and constant temperature

mal voltage, $N_{s}$ is the number of series cells in the module, $i_{\mathrm{pv}}$ is the delivered current and $v_{\mathrm{pv}}$ is the delivered voltage. The PV module used in the simulation is KC200GT [28], where its $\mathrm{I}-\mathrm{V}$ characteristics and the power-voltage $(\mathrm{P}-\mathrm{V})$ ones are displayed in Figs. 2 and 3, respectively.

\subsection{Boost converter model}

The boost converter is utilized as DC-DC stage to accomplish the MPPT task and increase the PV voltage to enable the grid connection. The converter has two modes (states) of operation based on the switch action OFF and ON. Figure 4 shows the boost converter circuit, where the most significant losses are considered. To be more specific, the inductor resistance, the voltage drop across the power switch and the voltage drop across the diode are included in this model.

Based on this configuration, the circuit behavior when the switch is OFF can be described as follows [29]

$$
\begin{aligned}
\frac{\mathrm{d} i_{l}}{\mathrm{~d} t} & =-\frac{R_{l}}{L} i_{l}+\frac{1}{L}\left(v_{\mathrm{pv}}-v_{d}-v_{\mathrm{dc}}\right), \\
\frac{\mathrm{d} v_{\mathrm{dc}}}{\mathrm{d} t} & =\frac{1}{c_{\mathrm{dc}}}\left(i-i_{\mathrm{inv}}\right),
\end{aligned}
$$

where $i_{1}$ is the inductor current, $v_{\mathrm{dc}}$ is the capacitor voltage, $L$ is the boost converter inductance, $R_{1}$ is the inductor par-

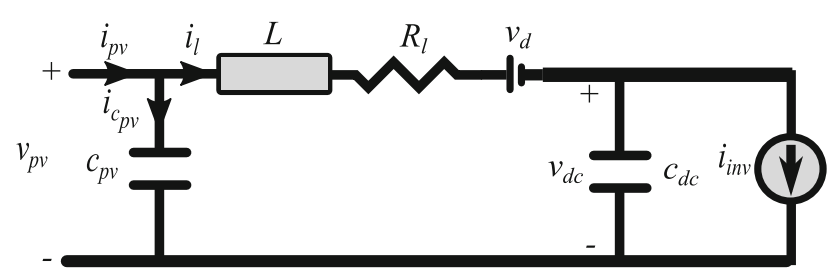

(a)

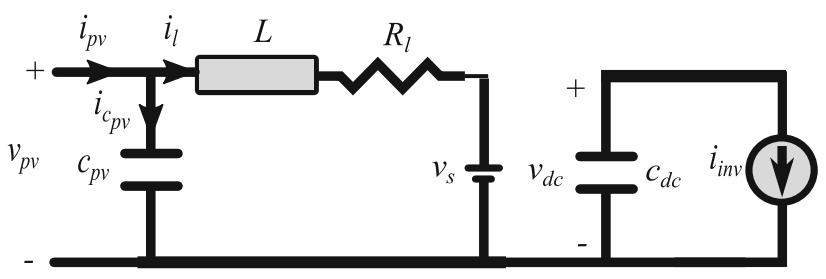

(b)

Fig. 4 Boost converter equivalent circuit when: a switch is OFF, and b switch is $\mathrm{ON}$

asitic resistance, $v_{d}$ is the drop across the diode when it is conducting, $i_{\text {inv }}$ is the inverter current and $c_{\mathrm{dc}}$ is the coupling capacitor value (between the boost and the two-level inverter). Further, when the switch is $\mathrm{ON}$ :

$$
\begin{aligned}
\frac{\mathrm{d} i_{l}}{\mathrm{~d} t} & =-\frac{R_{l}}{L} i_{l}+\frac{1}{L}\left(v_{\mathrm{pv}}-v_{s}\right), \\
\frac{d v_{\mathrm{dc}}}{\mathrm{d} t} & =-\frac{1}{c_{\mathrm{dc}}} i_{\mathrm{inv}} .
\end{aligned}
$$

where $v_{s}$ is the drop across the switch at ON state. Using the state space averaging technique, the boost model can be finalized as

$\dot{x}=\mathbf{A} x+\mathbf{B} u$,
$y=\mathbf{C} x+\mathbf{D} u$

where $x=\left[i_{1} v_{\mathrm{dc}}\right]^{\mathrm{T}}$ is the state vector, $u=\left[\left(v_{\mathrm{pv}}-v_{s}\right) i_{\mathrm{inv}}\right]^{\mathrm{T}}$ is the input vector, $y=v_{\mathrm{dc}}$ is the output and assume $v_{s}=$ $v_{d}$. Further, $\mathbf{A}, \mathbf{B}, \mathbf{C}$ and $\mathbf{D}$ are the system matrices and are expressed as follows

$\mathbf{A}=\left[\begin{array}{cc}-\frac{R_{l}}{L} & -\frac{1-d}{L} \\ \frac{1-d}{c_{\mathrm{dc}}} & 0\end{array}\right], \mathbf{B}=\left[\begin{array}{cc}\frac{1}{L} & 0 \\ 0 & -\frac{1}{c_{\mathrm{dc}}}\end{array}\right], \mathbf{C}=\left[\begin{array}{ll}0 & 1\end{array}\right], \mathbf{D}=0$,

where $d$ is the duty cycle of the boost converter. At steady state, the voltage gain of the boost converter and the efficiency can be evaluated as

$$
\begin{aligned}
G_{v} & =\frac{v_{\mathrm{dc}}}{v_{\mathrm{pv}}}=\frac{(1-d) v_{\mathrm{dc}}}{(1-d)^{2} v_{\mathrm{dc}}+(1-d) v_{s}+i_{\mathrm{dc}} R_{l}}, \\
\eta_{b} & =\frac{(1-d)^{2} v_{\mathrm{dc}}}{(1-d)^{2} v_{\mathrm{dc}}+(1-d) v_{s}+i_{\mathrm{dc}} R_{l}},
\end{aligned}
$$

where $i_{\mathrm{dc}}$ is the average value of $i_{\text {inv }}$. Figures 5 and 6 show the gain and the efficiency of the boost with the duty cycle 


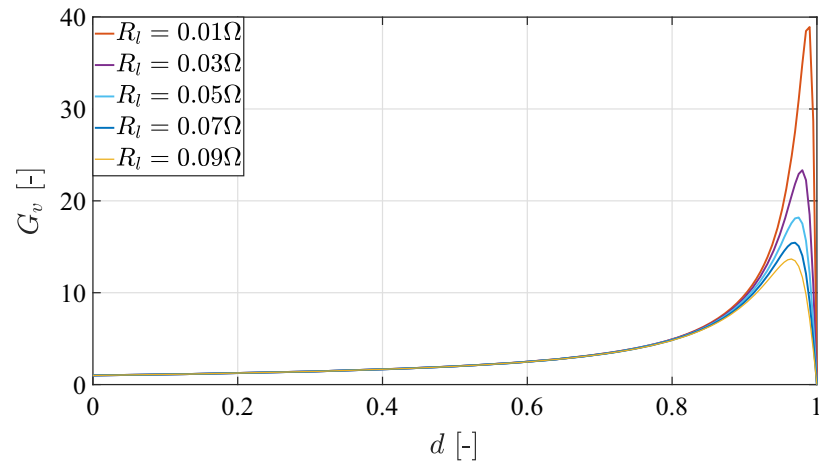

Fig. 5 Voltage gain with the duty cycle variation at different parasitic resistances of the inductor

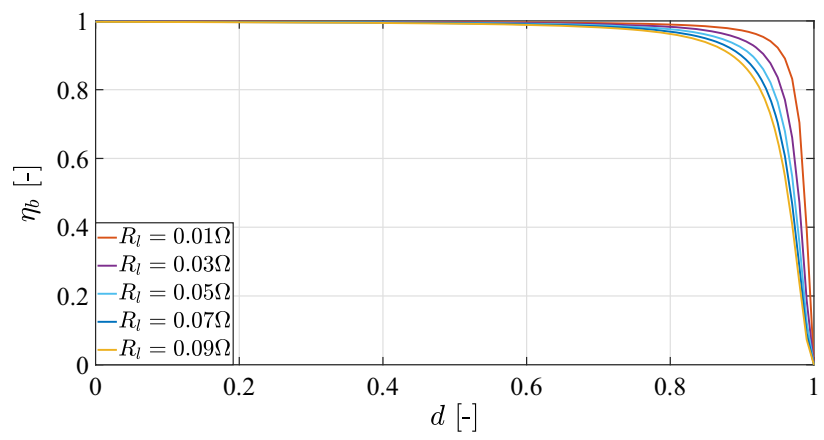

Fig. 6 Efficiency with the duty cycle variation at different parasitic resistances of the inductor

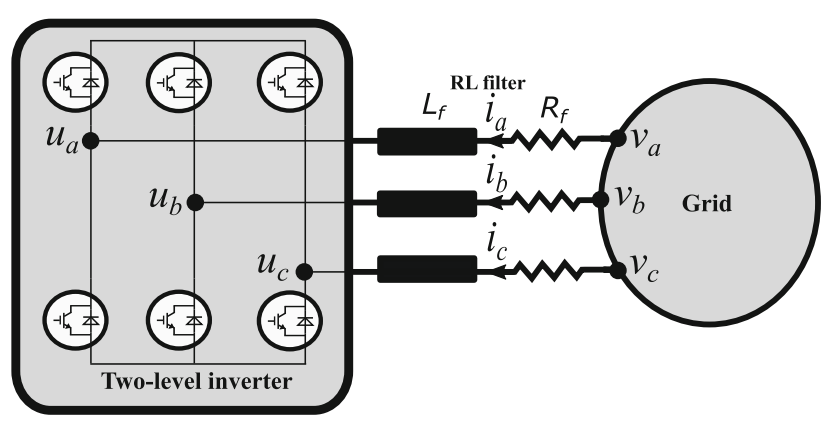

Fig. 7 Two-level inverter interfaced with RL filter for grid connection

variation. Notably, the voltage gain $\left(G_{v}\right)$ and the efficiency $\left(\eta_{b}\right)$ drop significantly at high duty cycles. Further, the more the parasitic resistance, the more the losses become; this can be observed by shifting the peak point of the gain curve to the left. The same happens for the knee point of the efficiency curve.

\subsection{Modeling of the two-level inverter with grid connection}

The inverter manages the active and reactive power control and converts the $\mathrm{DC}$ voltage to $\mathrm{AC}$ one for grid connection. Figure 7 presents the configuration of the two-level inverter tied to the utility. Applying KVL in this scheme, the following results [30]

$v_{a b c}=u_{a b c}+L_{f} \frac{d}{\mathrm{~d} t} i_{a b c}+R_{f} i_{a b c}$

where $v_{a b c}$ are the grid voltages, $i_{a b c}$ are the injected currents, $u_{a b c}$ are the inverter side voltages, $L_{f}$ is the filter inductance and $R_{f}$ is the filter resistance. Further, the output voltages of the inverter are given by

$u_{a b c}=\frac{1}{3}\left(v_{\mathrm{dc}}-2 v_{s}\right) T_{a b c} S_{a b c}$,

where $v_{\mathrm{dc}}$ is the coupling-capacitor voltage, $v_{\mathrm{s}}$ is the drop across the switches, $S_{a b c}$ is the switching state vector and $\in\{0,1\}$ and $T_{a b c}$ is the transformation matrix, which is expressed as

$T_{a b c}=\left[\begin{array}{ccc}2 & -1 & -1 \\ -1 & 2 & -1 \\ -1 & -1 & 2\end{array}\right]$.

In the stationary reference frame $(\alpha-\beta)$, Eq. (10) can be rewritten as

$v_{\alpha \beta}=u_{\alpha \beta}+L_{f} \frac{d}{\mathrm{~d} t} i_{\alpha \beta}+R_{f} i_{\alpha \beta}$,

where $i_{\alpha \beta}$ are the injected currents in $\alpha \beta$ reference frame. Furthermore, the rotating reference frame $(d-q)$ components of the voltages can be expressed as

$v_{d}=u_{d}+L_{f} \frac{d}{\mathrm{~d} t} i_{d}+R_{f} i_{d}-\omega L_{f} i_{q}$,

$v_{q}=u_{q}+L_{f} \frac{d}{\mathrm{~d} t} i_{q}+R_{f} i_{q}+\omega L_{f} i_{d}$,

where $i_{d q}$ are the injected currents in $d q$ reference frame, and $\omega$ is the grid frequency. Finally, the active and reactive power in $d-q$ reference frame are obtained as

$\begin{aligned} P & =\frac{3}{2}\left(v_{d} i_{d}+v_{q} i_{q}\right), \\ Q & =\frac{3}{2}\left(v_{q} i_{d}-v_{d} i_{q}\right) .\end{aligned}$

At steady state, the conversion efficiency of the inverter is calculated as

$\eta_{\mathrm{inv}}=\frac{v_{\mathrm{dc}} i_{\mathrm{dc}}-2 v_{s} i_{\mathrm{dc}}}{v_{\mathrm{dc}} i_{\mathrm{dc}}}=1-\frac{2 v_{s}}{v_{\mathrm{dc}}}$. 


\section{MPPT and inverter control}

MPPT is an essential operating regulation for PV systems. The extracted power from the PV source will be injected into the grid by inverter control. The details of the MPPT and the inverter control will be investigated in the coming subsections.

\subsection{MPPT}

As presented in Fig. 3, the $\mathrm{P}-\mathrm{V}$ curve exhibits a unique maximum power point at uniform radiation condition. The location of this point keeps changing as the atmospheric conditions change. Hence, to track this point, $\mathrm{P} \& \mathrm{O}$ algorithm is utilized. In this technique, the duty cycle (control parameter) is perturbed in one direction. For example, it is increased, and if the power increases, the duty cycle is further increased. Otherwise, the duty cycle will be decreased [31].

A remarkable drawback of this method is the continuous oscillations of the power at steady state. However, including adaptive step-size will limit the oscillations and enhance the efficiency [32]. This adaptive step can be refined as

$d(k)=d(k-1) \pm N\left|\frac{\mathrm{d} P}{\mathrm{~d} V}\right|$,

where $d(k)$ is the current duty cycle, $d(k-1)$ is the previous one, $N$ is a factor to be tuned and $\mathrm{d} P / \mathrm{d} V$ is the slope of the PV power with respect to the PV voltage. Figure 8 summarizes the steps for maximum power extraction using $\mathrm{P} \& \mathrm{O}$ method.

\subsection{Grid-connected inverter control using VOC}

The VOC is implemented in the $d-q$ reference frame by aligning the grid voltage vector with the $d$ axis. In this case, the active and reactive power (Equation (15)) can be rewritten as

$P=\frac{3}{2} v_{d} i_{d}$,

$Q=-\frac{3}{2} v_{d} i_{q}$.

As a result, the active and reactive power is decoupled from each other. Thus, the active and reactive power can be directly and independently controlled by controlling $i_{d}$ and $i_{q}$, respectively. Figure 9 shows the whole system control structure using adaptive MPPT and the VOC.

\section{Proposed sensorless DC-link control with PSO}

The VOC has two cascaded loops for active and reactive power control. However, in the suggested sensorless DC-link

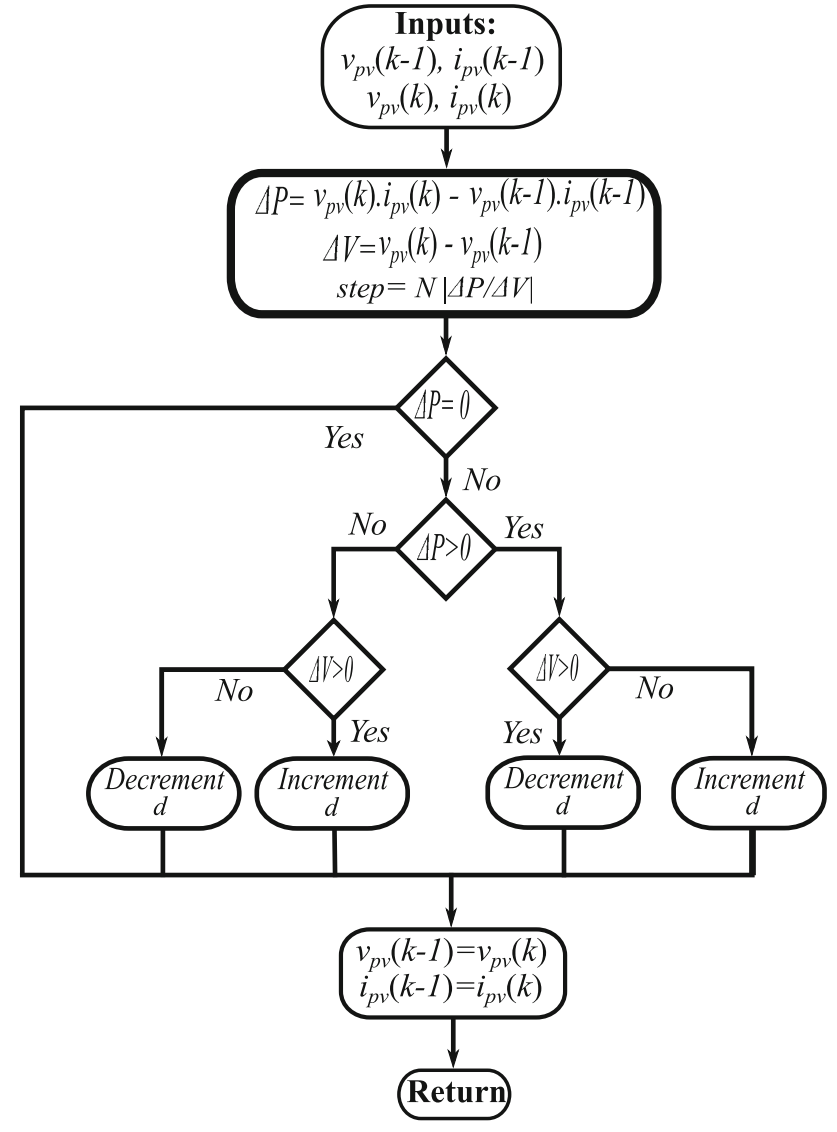

Fig. 8 P\&O method for MPPT with adaptive step-size

strategy, the outer loop is eliminated and the reference current $\left(i_{d r e f}\right)$ is generated according to the power balance technique at the DC-link. To guarantee this balance, the losses of the system are investigated based on a developed losses model of the system.

\subsection{Losses of the PV system}

The power balance at the DC-link must be achieved to assure constant DC-link voltage. This can be executed by injecting the extracted power from the PV source into the grid. However, the losses of the system must be compensated. Ideally, if the maximum generated power is injected into the grid, then the reference current is calculated as

$i_{\text {dref }}=\frac{2}{3} \frac{P_{\mathrm{pv}}}{v_{d}}$.

In practice, a portion of this power $\left(P_{\mathrm{pv}}\right)$ is lost in the system. Thus, injecting all the power into the grid causes reduction in the DC-link voltage. Such reduction may lead the modulation index of the pulse width modulated signals to cross unity. Hence, the total harmonic distortion (THD) of the currents will go beyond the limits and the output voltage of the inverter 


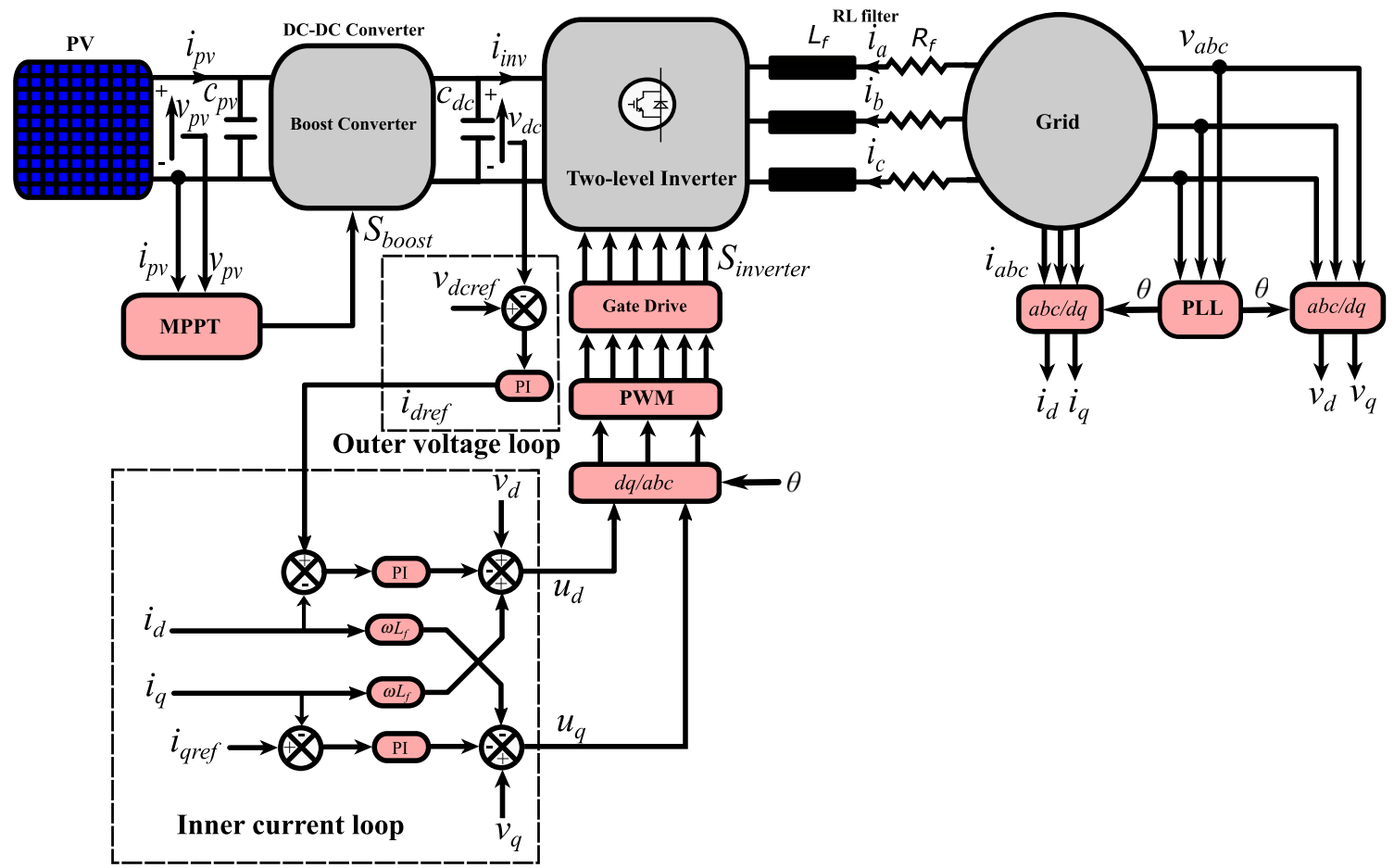

Fig. 9 Control structure of grid-connected PV inverter

will be distorted. Furthermore, the quality of the injected power will be deteriorated. Thus, it is crucial to account for the PV system losses. These losses can be sorted to converter losses and inverter losses, and they can be evaluated as

$P_{\text {loss }}^{1}=P_{\text {conv }}+P_{\mathrm{inv}}$.

According to the developed losses model, this can be further investigated as

$P_{\mathrm{loss}}^{1}=i_{l}^{2} R_{l}+i_{l} v_{s}+2 v_{s} i_{\mathrm{dc}}$

where $i_{l} \approx i_{\mathrm{pv}}$ and $i_{\mathrm{dc}}$ is the average value of $i_{\mathrm{inv}}$.

\subsection{Further losses compensation using PSO}

To guarantee power balance at the DC-link, another losses was added to the system to account for the unmodeled losses. It is assumed that the additional losses is proportional to the generated PV power at different radiation levels as follows

$P_{\text {loss }}^{2}=k_{\text {loss }} P_{\mathrm{pv}}$,

where $k_{\text {loss }}$ is the proportionality constant. For accurate estimation, PSO is used to tune this factor. It worth mentioning that the tuning process was adopted offline to reduce the computation burden. Furthermore, the tuning process considers different atmospheric conditions. PSO is a powerful optimization technique, which is used to solve different nonlinear engineering problems. Initially, PSO chooses a set of random values of the unknown parameters and each set is defined as a particle [33]. The fitness corresponding to each particle is calculated. Then, the particle with the best fitness is chosen and stored after each iteration of the algorithm, and lastly, the global optimum solution is obtained [34]. The flow chart of the PSO is shown in Fig. 10. Furthermore, the fitness function which is applied to choose the optimal parameter's value $\left(k_{\text {loss }}\right)$ is

$\min _{k_{\text {loss }}}=\sum\left|v_{\text {dcref }}-v_{\mathrm{dc}}\right|$

Finally, the complete system's losses is expressed as

$P_{\mathrm{loss}}^{t}=i_{l}^{2} R_{l}+i_{l} v_{s}+2 v_{s} i_{\mathrm{dc}}+k_{\mathrm{loss}} P_{\mathrm{pv}}$.

Based on this approach, the outer voltage loop is removed and the reference current is computed as

$i_{\text {dref }}=\frac{2}{3} \frac{P_{\mathrm{pv}}-P_{\text {loss }}^{t}}{v_{d}}$.

Figure 11 shows the modified outer voltage loop without PI controller. 


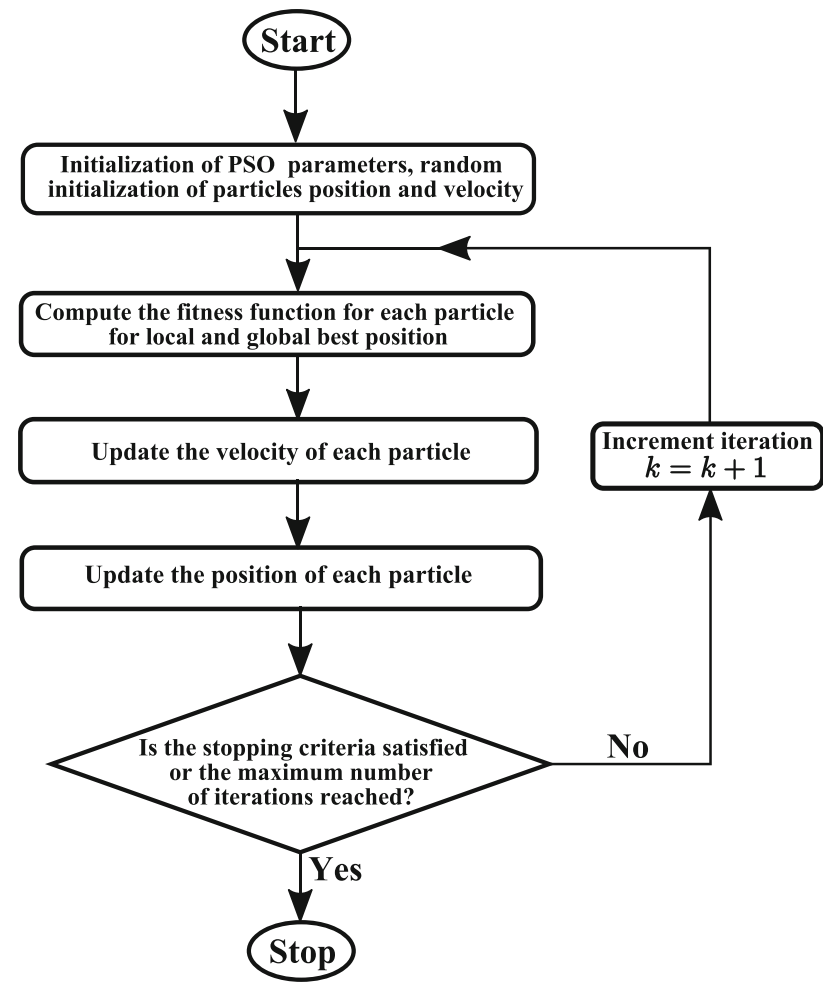

Fig. 10 PSO algorithm

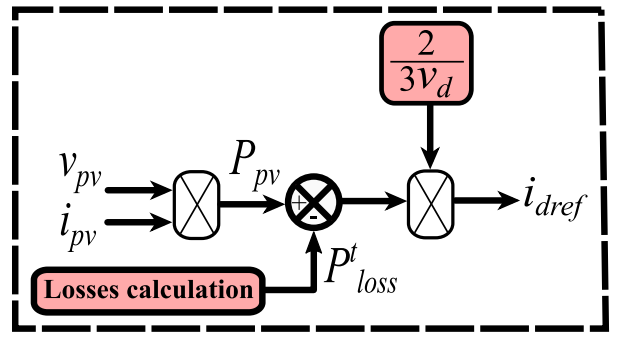

Fig. 11 Modified sensorless outer voltage loop

\section{Simulation results and discussion}

The grid-connected PV system consists of PV array of 15 $\mathrm{kW}$, arranged in series parallel configuration. The PV source is followed by a boost converter, which increases the PV voltage to a convenient value for grid integration. Further, the MPPT is implemented with an adaptive step-size perturb and observe method, and compared with the fixed step one. For active and reactive power control, the two-level inverter is controlled with sensorless DC-link voltage approach; in this technique the outer voltage loop is removed. Additionally, the proposed scheme is compared with the conventional VOC, which uses two-cascaded loop design. The details of the PV system model are summed up in Table 1. It is worth mentioning that the MPPT factor $(N)$ and the PI controller parameters are also tuned using PSO technique.
Table 1 PV grid-connected system parameters

\begin{tabular}{ll}
\hline Parameter & Value \\
\hline PV array power $(\mathrm{kW})$ & 15 \\
Boost inductance $L(\mathrm{mH})$ & 5 \\
Parasitic resistance $R_{l}(\Omega)$ & 0.01 \\
Switch and diode drops $\left(v_{s}=v_{d}\right)(\mathrm{V})$ & 1 \\
Switching frequency $f_{s}(\mathrm{kHz})$ & 10 \\
DC-link capacitance $c_{\mathrm{dc}}(\mu \mathrm{F})$ & 100 \\
Filter inductance $L_{f}(\mathrm{mH})$ & 5 \\
Filter resistance $R_{f}(\Omega)$ & 0.1 \\
DC-link reference voltage $v_{d c r e f}(\mathrm{~V})$ & 700 \\
Grid frequency $\omega(\mathrm{rad} / \mathrm{s})$ & $2 \pi \times 50$ \\
Grid line-line voltage $v(\mathrm{~V})$ & 400 \\
Sampling time $T_{s}[\mu \mathrm{s}]$ & 40 \\
\hline
\end{tabular}

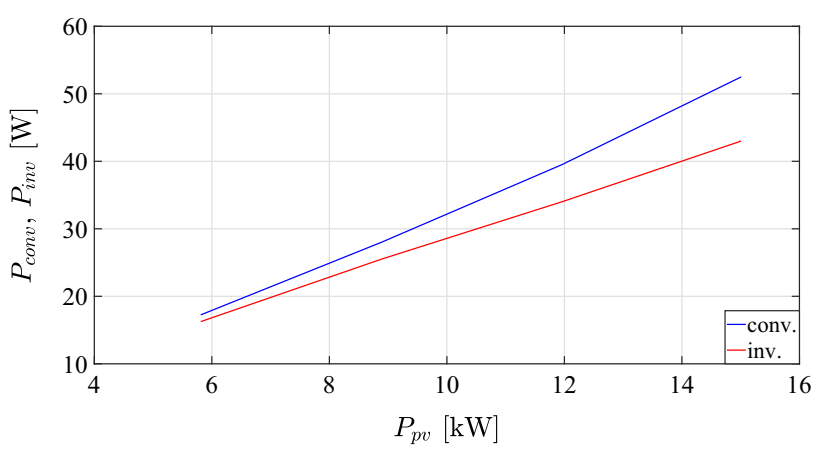

Fig. 12 Converter and inverter losses under different power levels

Table 2 Compensation factor value-based PSO at different atmospheric conditions

\begin{tabular}{lllll}
\hline Rad. $\left(\mathrm{W} / \mathrm{m}^{2}\right)$ & 400 & 600 & 800 & 1000 \\
\hline$P_{\mathrm{pv}}(k W)$ & 5.8110 & 8.8853 & 11.957 & 15.008 \\
$k_{\mathrm{loss}} \times 1 \cdot 10^{-3}$ & 0.94276 & 0.96103 & 0.98115 & 1.02544 \\
\hline
\end{tabular}

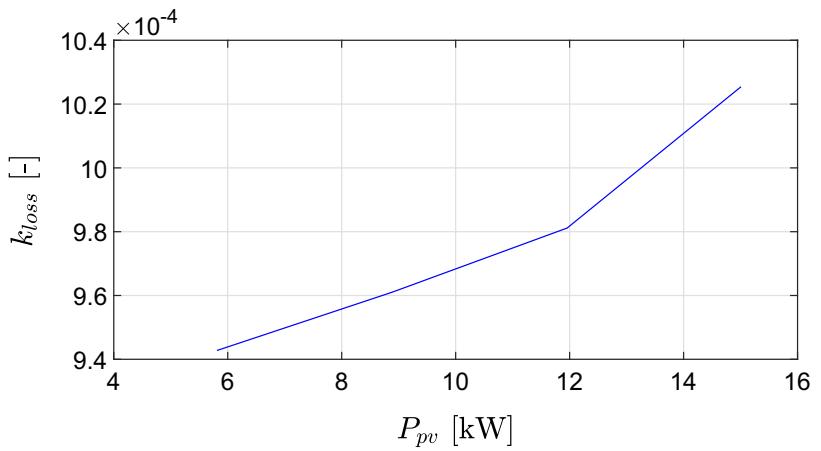

Fig. 13 Compensation factor under different power values 
Table 3 Compensation factor values according to the power level

\begin{tabular}{llll}
\hline Rad. $\left(\mathrm{W} / \mathrm{m}^{2}\right)$ & 400 & 700 & 1000 \\
\hline Power level $\left(P_{\mathrm{pv}}\right)$ & Low & Medium & High \\
$k_{\text {loss }} \times 1 \cdot 10^{-3}$ & 0.94276 & 0.97135 & 1.02544 \\
\hline
\end{tabular}

Figure 12 shows the converter and inverter losses at different power levels according to the developed losses model, where the inverter losses behavior is linear. However, the converter losses is varying according to quadratic function. Furthermore, the compensation factor $\left(k_{\text {loss }}\right)$ at different atmospheric conditions is tabulated in Table 2 and shown in Fig. 13. The behavior of the compensation factor is similar to the losses behavior as expected. Moreover, its values are limited to a narrow range. The reason is that the most significant losses have been modeled. Thus, a single factor can be used for the whole range of power generated from the PV source. However, and for practical implementation, three regions of power are chosen and defined as low, medium and high power levels. The corresponding values of $k_{\text {loss }}$ are computed at these power levels and given in Table 3. This can be simply implemented by a look-up table based on the $\mathrm{PV}$ power level, which is already known and extracted by the MPPT algorithm.

Figure 14 shows the MPPT performance with fixed and adaptive steps. The waveforms present the PV power, PV voltage, and $\mathrm{PV}$ current at different radiation conditions varying from 400 to $1000 \mathrm{~W} / \mathrm{m}^{2}$ at constant temperature of $25^{\circ} \mathrm{C}$. The results show that the fixed step suffers from higher under shoots as depicted in the PV voltage waveform. Additionally, the PV power exhibits higher ripple content. Adaptive $\mathrm{P} \& \mathrm{O}$ has the advantage of online adjustment of the step size, where the step-size is high far away from the maximum power point, and decreases as the algorithm approaches that point. That phenomena decrease the oscillations at steady state, and hence, the efficiency of the algorithm will be enhanced in comparison with fixed step size.

Figure 15 shows the DC-link capacitor voltage with the conventional VOC and the proposed sensorless DC-link strategy at the same radiation conditions, described previously in Fig. 14. The conventional VOC suffers from high overshoots in comparison with the proposed technique. However, the traditional VOC shows an enhanced start-up response in the beginning of the simulation. That is because of PI controller existence. In contrast, with the proposed approach, it eliminates the outer loop PI controller. Nevertheless, the proposed technique has a very fast response at different following radiation step changes with a very low overshoots as shown in Fig. 15. Furthermore, the proposed sensorless strategy has a very small steady state error. Table 4 gives a comparative analysis between the two techniques at different atmospheric conditions.

The active power, $\mathrm{d}$-axis current $\left(i_{d}\right)$, reactive power and q-axis current $\left(i_{q}\right)$ are presented in Fig. 16, respectively. It is worth mentioning that the atmospheric conditions are kept the same.

The $i_{d}$ of the conventional VOC exhibits a higher over shoot in comparison with the proposed one, in spite of the same PI controller's parameters of the two methods for the inner current loop. Furthermore, the conventional VOC presents a little bit slower transient response at different radiation conditions as revealed in Fig. 16. The active power also suffers from a slower transient behavior inherited from the $\mathrm{d}$-axis current. Besides, it has slightly higher ripple content in comparison with the sensorless proposed approach. The
Fig. 14 MPPT-based P\&O behavior with: a fixed step size, and $\mathbf{b}$ adaptive step size
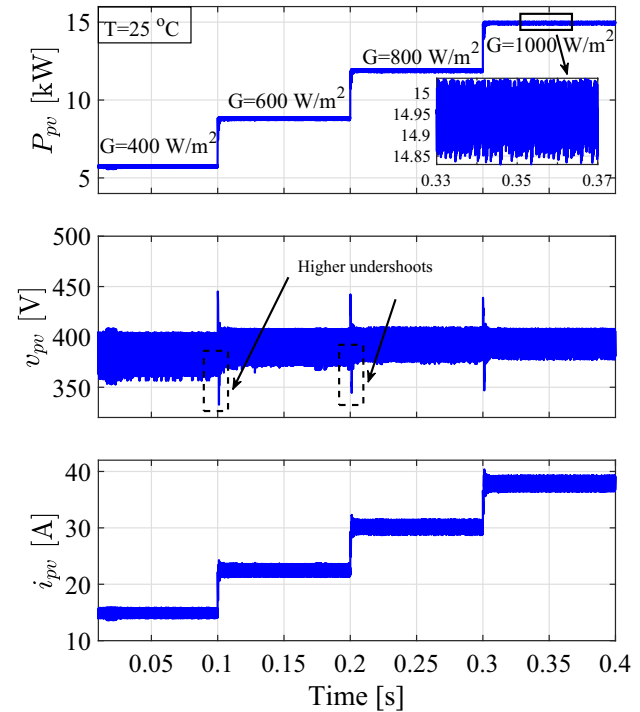

(a)
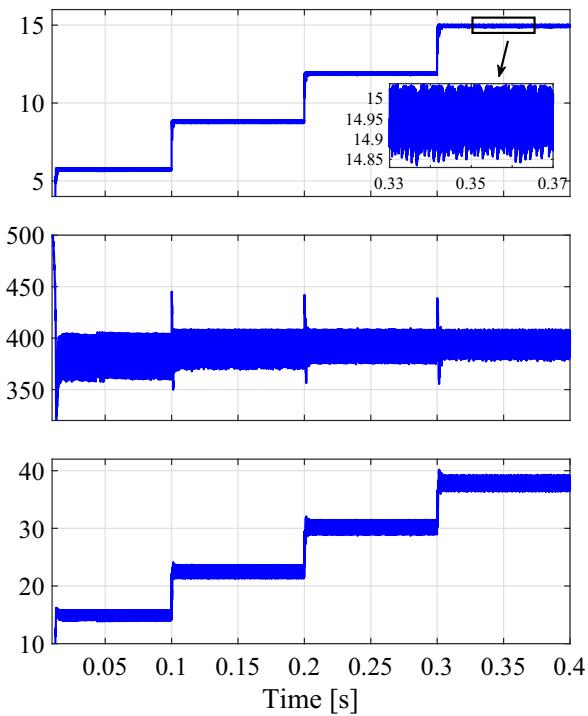

(b) 
Fig. 15 DC-link voltage with: a conventional VOC and $\mathbf{b}$ proposed sensorless DC-link

Fig. 16 Active power, d-axis current, reactive power, and q-axis current behavior with: a conventional VOC and $\mathbf{b}$ proposed sensorless DC-link

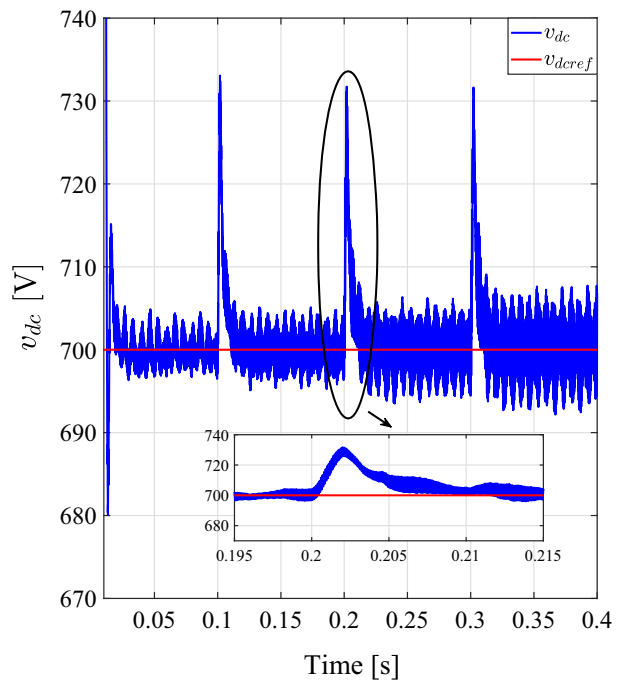

(a)
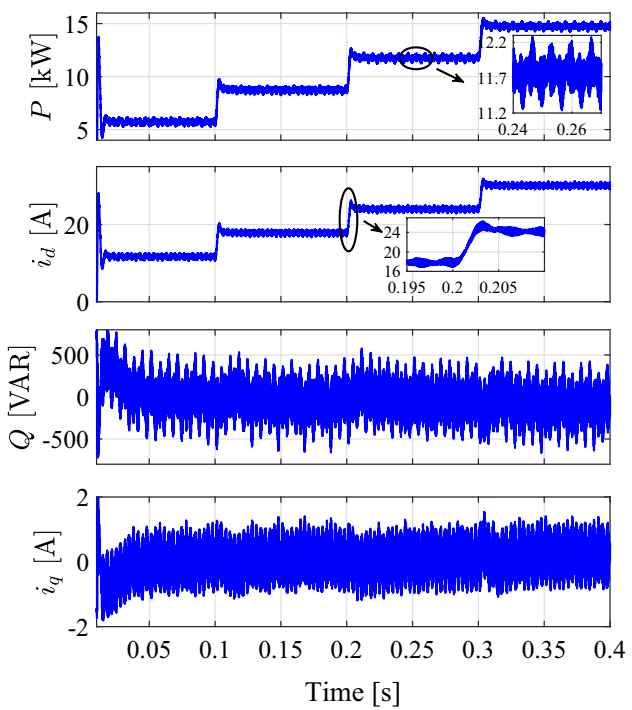

(a)

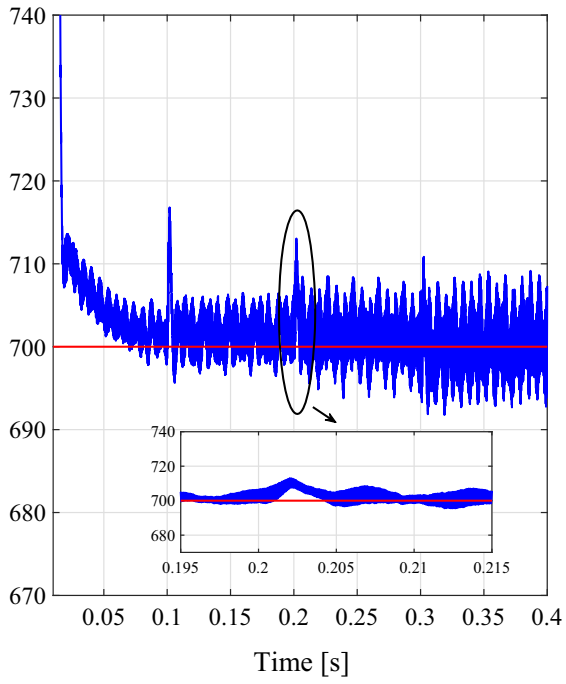

(b)
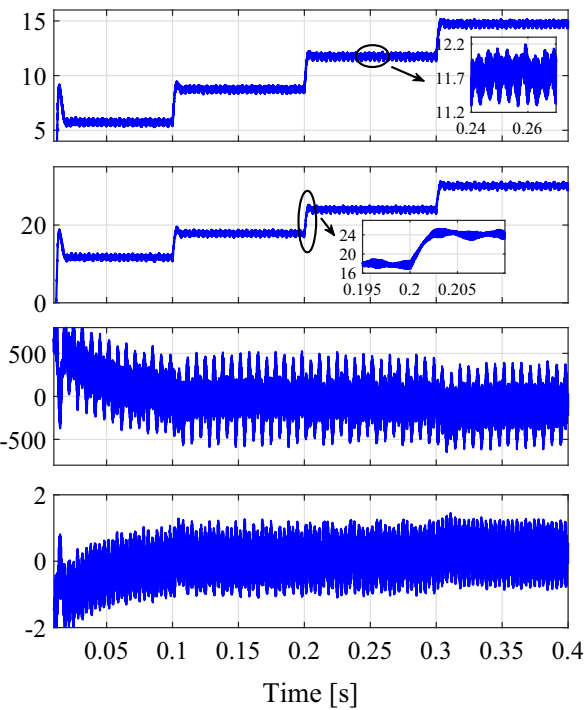

(b)
Table 4 Transient response comparison for the conventional VOC and the proposed sensorless technique

\begin{tabular}{|c|c|c|c|c|}
\hline \multirow[t]{2}{*}{ Condition $\left(\mathrm{W} / \mathrm{m}^{2}\right)$} & \multicolumn{2}{|c|}{ Conventional VOC } & \multicolumn{2}{|l|}{$\underline{\text { Sensorless VOC }}$} \\
\hline & Overshoot $(\%)$ & Settling time (ms) & Overshoot $(\%)$ & Settling time (ms) \\
\hline Start-up at 400 & 35.71 & 20 & 23.00 & 80 \\
\hline Step change from 400 to 600 & 4.71 & 12 & 2.43 & 5.20 \\
\hline Step change from 600 to 800 & 4.57 & 14 & 1.86 & 5.10 \\
\hline Step change from 800 to 1000 & 4.57 & 13 & 1.57 & 5 \\
\hline
\end{tabular}

reactive power response of the conventional VOC has some higher ripple profile in comparison with the proposed one. However, the reactive power waveform of the conventional technique shows an enhanced transient performance in the beginning of the simulation. Further, in the next intervals (radiation changes), the transient behavior of the two methods is very similar. The same applies for the q-axis current, where the reference current $\left(i_{\text {qref }}\right)$ is set to zero for unity power factor operation.

Figure 17 shows the three line currents $\left(i_{a b c}\right)$. The slowness of the traditional VOC also is inspected in the current profiles. Additionally, the overshoot is very obvious for the conventional scheme. However, the overshoots of the proposed sensorless DC-link strategy are small and at the 
Fig. 17 Three-phase currents with: a conventional VOC and $\mathbf{b}$ proposed sensorless DC-link

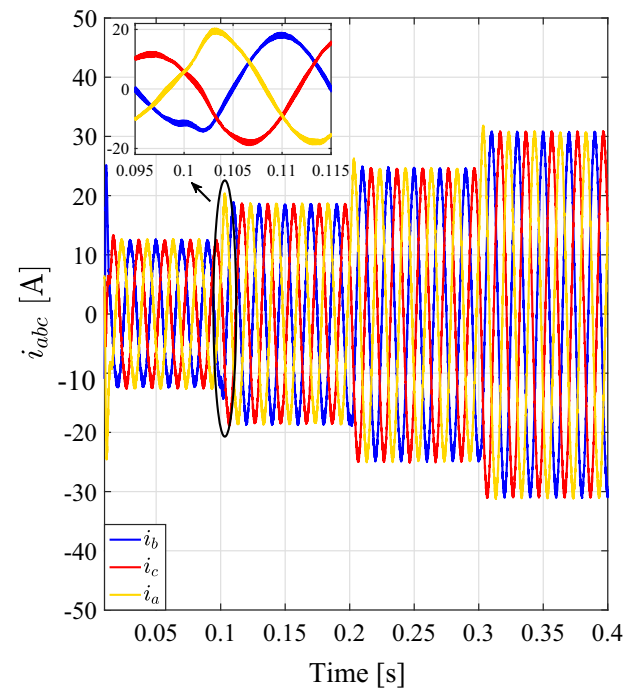

(a)

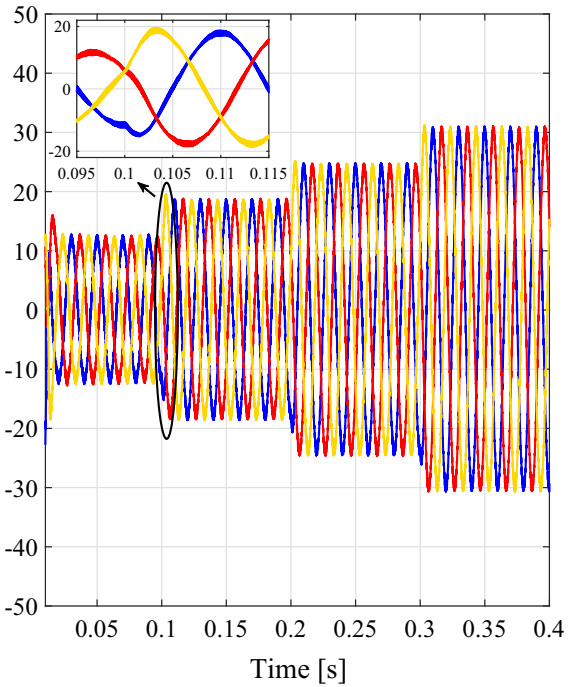

(b)
Table 5 THD of the currents with the conventional VOC and the proposed sensorless one

\begin{tabular}{lll}
\hline Condition $\left(\mathrm{W} / \mathrm{m}^{2}\right)$ & THD & \\
\cline { 2 - 3 } & Conventional (\%) & Proposed (\%) \\
\hline 400 & 4.55 & 4.49 \\
600 & 2.93 & 2.98 \\
800 & 2.24 & 2.26 \\
1000 & 1.77 & 1.81 \\
\hline
\end{tabular}

following step changes they further decrease. Table 5 summarizes the THD of the currents for the two techniques, where the two methods have quite similar THD values of the currents.

\section{Conclusion}

The detailed model of grid-connected PV system is investigated in this paper; even more the most significant losses in the system are included. The MPPT is managed using an adaptive step-size $\mathrm{P} \& \mathrm{O}$ method to reduce the potential steady state oscillations, instead of using fixed step. The traditional cascaded VOC loops are avoided in this research by eliminating the outer PI controller loop, and hence, sensorless DC-link control strategy is achieved. The proposed approach guaranties the power balance at DC-link by developing an accurate losses model of the system, in which the power that should be injected into the grid is calculated directly from the MPPT scheme and the losses of the system. Thus, the reference current can be directly estimated without the need of the outer PI controller. Furthermore, the PSO algorithm is used to compensate for the unaccounted losses in the model and to tune the MPPT factor and PI controller parameters. However, the algorithm is implemented offline to reduce the computational load. The proposed technique eliminates the DC-link voltage sensor. This in turn decreases the system cost and increases the reliability. Besides, the overall control structure is simplified by avoiding the two cascaded loops of the conventional VOC. The results show that the proposed sensorless strategy has an improved transient response in most of the operating conditions as compared with the conventional technique. Furthermore, the overshoots in the DC-link voltage are greatly reduced. Finally, the quality of the injected power with the proposed technique is enhanced and the THD of the currents is very similar.

Open Access This article is licensed under a Creative Commons Attribution 4.0 International License, which permits use, sharing, adaptation, distribution and reproduction in any medium or format, as long as you give appropriate credit to the original author(s) and the source, provide a link to the Creative Commons licence, and indicate if changes were made. The images or other third party material in this article are included in the article's Creative Commons licence, unless indicated otherwise in a credit line to the material. If material is not included in the article's Creative Commons licence and your intended use is not permitted by statutory regulation or exceeds the permitted use, you will need to obtain permission directly from the copyright holder. To view a copy of this licence, visit http://creativecomm ons.org/licenses/by/4.0/.

\section{References}

1. Panwar NL, Kaushik SC, Surendra K (2011) Role of renewable energy sources in environmental protection: a review. Renew Sustain Energy Rev 15(3):1513-1524

2. Prabodh B, Vaishalee D (2012) Hybrid renewable energy systems for power generation in stand-alone applications: a review. Renew Sustain Energy Rev 16(5):2926-2939

3. Marco L, Thilo S, Hung John Y (2010) Future energy systems: integrating renewable energy sources into the smart power grid through industrial electronics. IEEE Ind Electron Mag 4(1):18-37 
4. Atika Q, Fayaz H, Rahim Nasrudin ABD, Glenn H, Daniyal A, Khaled S, Khalid H (2019) Towards sustainable energy: a systematic review of renewable energy sources, technologies, and public opinions. IEEE Access 7:63837-63851

5. Sahu Bikash Kumar (2015) A study on global solar PV energy developments and policies with special focus on the top ten solar PV power producing countries. Renew Sustain Energy Rev 43:621634

6. Wirth H, Schneider K (2015) Recent facts about photovoltaics in Germany. Fraunhofer ISE 92

7. Nadarajah K, Divagar V (2016) Solar energy for future world: a review. Renew Sustain Energy Rev 62:1092-1105

8. Alajmi Bader N, Ahmed Khaled H, Philip AG, Williams Barry W (2012) Single-phase single-stage transformer less grid-connected PV system. IEEE Trans Power Electron 28(6):2664-2676

9. Zakzouk Nahla E, Abdelsalam Ahmed K, Helal Ahmed A, Williams Barry W (2016) PV single-phase grid-connected converter: dc-link voltage sensorless prospective. IEEE J Emerg Sel Top Power Electron 5(1):526-546

10. Li H, Xu Y, Adhikari S, Rizy DT, Li F, Irminger P (2012) Real and reactive power control of a three-phase single-stage PV system and PV voltage stability. In: 2012 IEEE power and energy society general meeting, pp 1-8. IEEE

11. Vinit K, Mukesh S (2019) Sensorless DC-link control approach for three-phase grid integrated PV system. Int J Electr Power Energy Syst 112:309-318

12. Frede B, Remus T, Marco L, Timbus Adrian V (2006) Overview of control and grid synchronization for distributed power generation systems. IEEE Trans Ind Electron 53(5):1398-1409

13. Joan R, Alvaro L, Frede B, Pedro R (2012) Control of power converters in AC microgrids. IEEE Trans Power Electron 27(11):4734-4749

14. Aguilera Ricardo P, Quevedo Daniel E, Vzquez Sergio, Franquelo Leopoldo G (2013) Generalized predictive direct power control for ac/dc converters. In: 2013 IEEE ECCE Asia Downunder, pp 1215-1220. IEEE

15. Yongchang Z, Zhengxi L, Yingchao Z, Wei X, Zhengguo $P$, Changbin $H$ (2012) Performance improvement of direct power control of PWM rectifier with simple calculation. IEEE Trans Power Electron 28(7):3428-3437

16. Riad K, Jean-Paul G, Gerard C (2010) An improved maximum power point tracking for photovoltaic grid-connected inverter based on voltage-oriented control. IEEE Trans Industr Electron 58(1):6675

17. Kamel B, Djamel R (2014) Predictive direct power control for photovoltaic grid connected system: an approach based on multilevel converters. Energy Convers Manage 78:825-834

18. Zanchetta P, Cortes P, Perez M, Rodriguez J, Silva C (2011) Finite states model predictive control for shunt active filters. In: IECON 2011-37th annual conference of the IEEE industrial electronics society, pp 581-586. IEEE

19. Jiefeng H, Jianguo Z, Dorrell David G (2014) Model predictive control of grid-connected inverters for PV systems with flexible power regulation and switching frequency reduction. IEEE Trans Ind Appl 51(1):587-594

20. Yong Y, Huiqing W, Depeng L (2017) A fast and fixed switching frequency model predictive control with delay compensation for three-phase inverters. IEEE Access 5:17904-17913

21. Sergio V, Leon Jose I, Franquelo Leopoldo G, Jose R, Young Hector A, Abraham M, Pericle Z (2014) Model predictive control: a review of its applications in power electronics. IEEE Ind Electron Mag $8(1): 16-31$

22. Mohamed A, Michael HC, Ralph K (2017) Simplified model predictive current control without mechanical sensors for variablespeed wind energy conversion systems. Electr Eng 99(1):367-377
23. Abd Rahim N, Selvaraj J(2007) Hysteresis current control and sensorless MPPT for grid-connected photovoltaic systems. In: 2007 IEEE international symposium on industrial electronics, pp 572577. IEEE

24. Meza C, Biel D, Negroni J, Guinjoan F (2005) Boost-buck inverter variable structure control for grid-connected photovoltaic systems with sensorless MPPT. In: Proceedings of the IEEE international symposium on industrial electronics, 2005. ISIE 2005, vol 2, pp 657-662. IEEE

25. Bo Y, Wuhua L, Yi Z, Xiangning H (2010) Design and analysis of a grid-connected photovoltaic power system. IEEE Trans Power Electron 25(4):992-1000

26. Sreeraj ES, Kishore C, Santanu B (2012) One-cycle-controlled single-stage single-phase voltage-sensorless grid-connected PV system. IEEE Trans Industr Electron 60(3):1216-1224

27. Mostafa A, Mohamed A, Ralph K (2020) Highly efficient and robust grid connected photovoltaic system based model predictive control with kalman filtering capability. Sustainability 12(11):4542

28. Salam Z, Ishaque K, Taheri H (2010) An improved two-diode photovoltaic (PV) model for PV system. In: 2010 joint international conference on power electronics, drives and energy systems \& 2010Power India, pp 1-5. IEEE

29. Mohan N, Undeland TM, Robbins WP (2003) Power electronics: converters, applications, and design. Wiley, New York

30. Christian D, Christoph H, Korbinian S (2015) Modellierung und Regelung von modernen Windkraftanlagen: Eine Einfhrung. Elektrische Antriebe-Regelung von Antriebssystemen. Springer, Berlin, pp 1540-1614

31. Ankit G, Chauhan Yogesh K, Kumar PR (2016) A comparative investigation of maximum power point tracking methods for solar PV system. Sol Energy 136:236-253

32. Fangrui L, Shanxu D, Fei L, Bangyin L, Yong K (2008) A variable step size INC MPPT method for PV systems. IEEE Trans Industr Electron 55(7):2622-2628

33. Marco C, Mauro C, Andrea F, Mario M (2014) PSO-based selfcommissioning of electrical motor drives. IEEE Trans Industr Electron 62(2):768-776

34. Ahmed F, Mohamed A, Amr S, Adel S, Ralph K (2020) Simplified sensorless current predictive control of synchronous reluctance motor using online parameter estimation. Energies 13(2):492

Publisher's Note Springer Nature remains neutral with regard to jurisdictional claims in published maps and institutional affiliations. 